\title{
Masseter muscle tension, chewing ability, and selected parameters of physical fitness in elderly care home residents in Lodz, Poland
}

This article was published in the following Dove Press journal:

Clinical Interventions in Aging

22 July 2014

Number of times this article has been viewed

Ewelina Gaszynska'

Malgorzata Godala ${ }^{2}$

Franciszek Szatko'

Tomasz Gaszynski ${ }^{3}$

'Department of Hygiene and Health Promotion, Medical University of Lodz, Poland; ${ }^{2}$ Department of Nutrition and Epidemiology, Medical University of Lodz, Poland; ${ }^{3}$ Department of Emergency Medicine and Disaster Medicine, Medical University of Lodz, Poland
Correspondence: Tomasz Gaszynski Department of Emergency Medicine and Disaster Medicine, Barlicki University Hospital, ul. Czechoslowacka 2b,

92-216 Lodz, Poland

Tel +48 422725747

Email tomasz.gaszynski@umed.lodz.pl
Background: Maintaining good physical fitness and oral function in old age is an important element of good quality of life. Disability-related impairment of oral function contributes to a deterioration of the diet of older people and to the reduction of their social activity.

Objectives: Investigate the association between masseter muscle tension, dental status, and physical fitness parameters.

Materials and methods: Two hundred fifty-nine elderly care home residents ( 97 men, 162 women; mean age, $75.3 \pm 8.9$ years) were involved in this cross-sectional study. Their chewing ability was evaluated by masseter muscle tension palpation, differences of masseter muscle thickness, self-reported chewing ability, number of present and functional teeth, and number of posterior tooth pairs. Masseter muscle thickness was measured by ultrasonography. To assess physical fitness, hand grip strength and the timed up-and-go test were performed. Nutritional status was assessed using body mass index and body cell mass index (BCMI), calculated on the basis of electrical bioimpedance measurements. Medical records were used to collect information on systemic diseases and the number of prescribed medications. Subjects were also evaluated for their ability to perform ten activities of daily living.

Results: Ninety-seven percent of the subjects suffered from systemic diseases. The three most prevalent illnesses were cardiac/circulatory $64.5 \%$, musculoskeletal $37.3 \%$, and endocrine/ metabolic/nutritional $29.3 \%$. Of the participants, $1.5 \%$ were underweight and more than one third (34.4\%) were overweight. Malnutrition (BCMI below normal) was found in almost half (45.2\%) of the subjects. Only $5.8 \%$ had a sufficient number of functional natural teeth. Statistically significant correlations were found between palpation of masseter muscle tension and perceived chewing ability, number of present teeth, number of functional teeth, number of posterior tooth pairs, timed up-and-go, hand grip strength, body mass index, BCMI, and activities of daily living. In a multivariate model, after adjusting for age, sex, and education, subjects with higher BCMI, higher hand grip strength, and more present teeth had a significantly higher chance of strong masseter muscle tension.

Conclusion: There is a relationship between chewing ability and physical fitness in elderly people. Efficiency of masseter muscles is related to physical fitness in the elderly. Masseter muscle tension examined by palpation can be used in public dentistry as one of the indicators of quality of life.

Keywords: physical fitness, chewing ability, masseter muscle tension

\section{Background}

Decrease in physical performance and oral function are common and potentially serious problems of the elderly. ${ }^{1,2}$ Age-related impairment of those characteristics is associated with adverse pathophysiological changes, leading to loss of mass of the 
skeletal muscles and lower efficiency. Ultrasonographic tests have revealed a correlation between the mass of the masseter muscles and that of limb muscles. ${ }^{3}$ Some authors suggest that the same mechanisms that are responsible for the changes in skeletal muscle may also act on the masseter muscles. ${ }^{4}$ Some other authors, in contrast, suggest that the masseter muscles do not become weaker or that they become weaker with age to a lesser extent when the teeth are present. ${ }^{5}$ Other factors contributing to the loss of muscle mass and decrease in muscle strength, in addition to age and genetic factors, include unhealthy diet, limited physical activity, and chronic diseases. ${ }^{6,7}$ Masticatory function is one of the most important oral functions in elderly people. Preserving of masticatory function is essential for sustaining life itself and for good quality of life. ${ }^{8-10}$ Most authors have assessed perceived chewing ability and dental status. Correlations have been shown to occur between perceived chewing ability and leg extensor strength, after adjustment for serum albumin and fasting glucose levels; ${ }^{11}$ between lower extremity performance and dental status; ${ }^{12}$ and between dental status and locomotion. ${ }^{13}$ It was also found that people with 20 or more remaining teeth show greater social and physical activity. ${ }^{14}$

However, there are a limited number of studies focusing on the physical fitness and nutritional status of elderly people and their masticatory function/chewing ability, taking into account the masseter muscle tension. ${ }^{4}$

\section{Materials and methods Subjects}

The study included people aged 65 years and older living in seven care homes in Lodz, a city located in central Poland. The inclusion criteria were adequate cognitive function for understanding the procedures and being able to give written informed consent. Elderly patients with impaired cognitive function, who were after limb amputation, and who were affected by terminal disease were excluded from the study. Of 315 subjects, 259 (97 men, 162 women; mean age, 75.3 \pm 8.9 years [range, 65-99 years]) ultimately agreed to participate. Ten people with pacemakers were excluded from the study stage involving measurement of electrical impedance. The study was approved by the Medical University Ethics Committee (No. RNN/181/13/KB).

Chewing ability assessment was carried out on a makeshift dental bench by a single dentist. ${ }^{15}$ The following data were recorded: number of present teeth (the number of healthy teeth + number of teeth treated + number of teeth with caries), number of functional teeth in contact with the opposite teeth (number of healthy teeth + number of teeth treated + number of teeth with caries + number of artificial teeth on prostheses), number of posterior tooth pairs (maximum, eight pairs). The teeth with clinical crowns shorter than $2 \mathrm{~mm}$ or with extensive carious lesion and third molars were not included.

Palpation of masseter muscle tension was performed. The researcher placed her four fingers on the face of the subject over the masseter muscle; the subject was asked to relax muscles to check the status of masseter muscle laxity, and then he/she was asked to bite forcefully with the molars in contact. Masseter muscle tension was classified as strong, weak, nil (strong, fingertips are pushed firmly, it is possible to feel the hardness of the masseter; weak, fingertips are pushed very feebly, hardness of the masseter is scarcely perceptible; nil, fingertips are not pushed, no perceptible hardness of the masseter muscle). ${ }^{16}$

Masseter muscle tension was then determined by ultrasonography. The study subject was sitting in a chair with no support to the head, positioned so the Frankfurt plane was parallel to the floor and the thickness of the muscle was tested unilaterally. The probe was placed perpendicular to the mandibular branch at the earlier palpated thickest part of the muscle (unilaterally, using a real-time ultrasound scanner and a $6 \mathrm{MHz}$ linear-array transducer); to avoid tissue compression, ultrasound contact gel was applied onto the probe (Micromaxx; SonoSite, Bothell, WA, USA). The thickness of the muscle was determined at rest and then with the teeth at maximum contact. The difference of those two measurements was used in the analysis.

\section{Self-reported chewing ability}

Participants were asked to select one of the four most appropriate sentences describing their chewing ability: "I can chew all I want to eat"; "I can chew almost anything I want to eat except hard foods"; "Selection of foods that I can eat is limited by my chewing ability"; and "I can barely chew anything." Then these 4 options were grouped as good (option 1 or 2 replies) or poor (option 3 or 4 replies) chewing ability.

\section{Upper and lower extremity performance}

Upper extremity performance hand grip strength (HGS) was measured. Isometric HGS was measured by a handheld dynamometer (Dynex I; Akern Srl, Pontassieve, Italy; MD Systems Inc., Westerville, OH, USA) in participants seated with upper limb bent at an angle of $90^{\circ}$. The average value of two consecutive measurements of the grip of the dominant hand was recorded. 
The timed up-and-go (TUG) test was used ${ }^{17}$ to assess lower extremity performance. To standardize the testing conditions, all measurements were performed on a smooth surface, and all participants were barefoot.

\section{Nutritional status}

Nutritional status was evaluated using the body mass index (BMI) and the body cell mass index (BCMI). Subject's height was calculated from the measurement of demispan. ${ }^{18}$ Body weight was measured using the medical scale. The subjects were classified as underweight $\left(<18.5 \mathrm{~kg} / \mathrm{m}^{2}\right)$, normal range ( $\geq 18.5$ to $\left.<25 \mathrm{~kg} / \mathrm{m}^{2}\right)$, and overweight $\left(\geq 25 \mathrm{~kg} / \mathrm{m}^{2}\right.$ ) according to the classification of BMI by the World Health Organization. ${ }^{19}$ Body impedance was measured using Bodycomp MF Plus (Akern Srl), according to the manufacturer's instructions. Electrodes were attached to the foot and hand on the same side of the body in a subject in relaxed, supine position. The machine uses the frequency range $5-50-100 \mathrm{kHz}$. The BCMI was calculated as body cell mass/height squared. The subjects were classified as normal range for men if BCMI is greater than $10 \mathrm{~kg} / \mathrm{m}^{2}$, and for women if BCMI is greater than $7.5 \mathrm{~kg} / \mathrm{m}^{2}$. BMI and BCMI were calculated using the Bodygram MF Plus v. 1.2 for Windows software package (Akern Srl). Body cell mass is the metabolically active part of the body weight. Its main part consists of skeletal muscles and also includes viscera, organs, blood, and brain tissue. ${ }^{20}$

Subjects were evaluated for their ability to perform the activities of daily living (ADL) by a nurse or the medical carer, using the modified 20-point Barthel Index (20 points independent, 19-9 dependent in some of 10 activities, 8-0 dependent in most of 10 activities).

Information about systemic ailments and the number of prescribed medications were extracted from the medical records of the subjects. Demographic data including age, sex, and education were also recorded.

\section{Statistical analyses}

Spearman's correlation coefficient was applied when testing the association between two continuous variables. The Kruskal-Wallis test was used to analyze continuous variable distribution differentiation on categorical variable categories. Multiple logistic regression analysis was used to test the association between masseter muscle tension (dichotomous variable: strong versus weak or nil) and dental status, nutritional status, and physical fitness. The level of significance was set at 0.05 . Quality assurance of data transfer from paper records was carried out by monitoring every tenth record.
Statistica version 10.0 (StatSoft, Tulsa, OK, USA) was applied for statistical analysis.

\section{Results \\ General health and nutritional status}

As many as $97 \%$ of subjects had systemic ailments, including $64.5 \%$ cardiac/circulatory, $37.3 \%$ musculoskeletal, $29.3 \%$ endocrine/metabolic/nutritional, $13.1 \%$ pulmonary, and $15.7 \%$ neurologic disorders. The mean number of prescribed medication was $6.9 \pm 2.9$, and the range was from 1-16 medications. ADLs range was 9-20, and 34.4\% were categorized as independent and $65.6 \%$ as partially dependent.

Average HGS of the participants was low. Mean HGS was $27.67 \pm 6.17 \mathrm{~kg}$ for men (range, 13.2-44.5 kg) and $13.71 \pm 5.14 \mathrm{~kg}$ for women (range, $2.5-25.9 \mathrm{~kg}$ ). Mean TUG was $10.35 \pm 4.38$ seconds for men (range, $6.9-25$ seconds) and $12.92 \pm 5.56$ seconds for women (range, 6.9-30 seconds).

Of the respondents, $1.5 \%$ were underweight, $64.1 \%$ were within the normal range, and $34.4 \%$ were overweight. Overweight was found in $41.2 \%$ of men and $30.3 \%$ of women. In contrast, malnutrition (BCMI below normal) was observed in $45.2 \%$ of the respondents: more than half $(56.7 \%)$ of men and more than one third (38.3\%) of the women.

Mean difference in the masseter muscle thickness (DMMT) for men and women was $3 \pm 0.79$ and $2.1 \pm 0.72 \mathrm{~mm}$, respectively. Strong masseter muscle tension was observed in $59.8 \%$ (58) of the men and $32.1 \%$ (52) of the women, and no tension was seen in 10.3\% (10) of the men and 16\% (26) of the women (Table 1). A sufficient number (20 or more) of present teeth was noted only in 15 participants (5.8\%).

Correlation was found to occur between the number of present teeth and BCMI and HGS (positive correlation), number of present teeth and number of prescribed medications (negative correlation), and number of posterior tooth pairs and TUG (negative correlation) (Table 2).

DMMT was positively associated with the number of functional teeth, the number of posterior occluding tooth pairs, HGS, BCMI, BMI, and ADL and was negatively associated with TUG test (Table 2).

It was found that the number of teeth present, number of functional teeth, pairs of posterior teeth, HGS, BCMI, and BMI were significantly different between the groups, categorized according to palpation-assayed masseter muscle tension (Table 3). Because of the small group size, in further analysis, masseter muscle nil- and low-tension groups were combined into a single group. 
Table I Chewing ability variables and demographics

\begin{tabular}{|c|c|c|c|c|}
\hline Variable & Total & Male & Female & P-value \\
\hline Age (years), mean \pm SD & $75.3 \pm 8.9$ & $70.4 \pm 6.3$ & $78.2 \pm 9.0$ & $<0.001^{a}$ \\
\hline Present teeth $(n)$, mean $\pm S D$ & $5.6 \pm 7.3$ & $6.8 \pm 7.9$ & $4.9 \pm 6.9$ & $0.07^{\mathrm{a}}$ \\
\hline Functional teeth $(n)$, mean $\pm S D$ & $14.6 \pm 12.4$ & $14.8 \pm 11.9$ & $14.5 \pm 12.8$ & $0.93^{\mathrm{a}}$ \\
\hline Posterior tooth pairs $(n)$, mean $\pm S D$ & $3.8 \pm 3.7$ & $3.8 \pm 3.6$ & $3.8 \pm 3.7$ & $0.93^{\mathrm{a}}$ \\
\hline Difference in the masseter muscle thickness, mean $\pm S D$ & $2.4 \pm 0.85$ & $3 \pm 0.79$ & $2.1 \pm 0.72$ & $0.00^{\mathrm{a}}$ \\
\hline Self-reported chewing ability, \% good & 51.3 & 51.5 & 51.2 & $1.00^{\mathrm{b}}$ \\
\hline Palpation masseter muscle tension, \% strong & 42.5 & 59.8 & 32.1 & $<0.00 \mathrm{I}^{\mathrm{b}}$ \\
\hline
\end{tabular}

Notes: ${ }^{a}$ Kruskal-Wallis test. ${ }^{b} \mathrm{Chi}$-squared test.

Abbreviation: SD, standard deviation.

In a multivariate model, after adjusting for age, sex, and education, subjects with higher BCMI, higher HGS, and more present teeth had a significantly higher chance for strong masseter muscle tension.

Multiple logistic regression model was used to estimate odds/chance for strong masseter muscle tension in association with physical fitness parameters, systemic diseases, ADLs, number of prescribed medications, nutritional status, and dental status (Table 4). After adjusting for age, sex, and level of education, statistically significant relationships were found to occur only between masseter muscle tension and the number of present teeth, HGS, and BCMI. Subjects with higher BCMI, higher HGS, and more present teeth had a significantly higher chance for strong masseter muscle tension.

\section{Discussion}

There is a correlation between chewing ability and physical fitness and nutritional status.

The prevalence of systemic diseases was similar in the study population compared with the general population of elderly people in Poland; multiple diseases and multimedication therapies were frequent. ${ }^{21}$

However, the proportion of overweight people in study participants was smaller than that estimated in the Polish general population of the elderly people older than 65 years (70\% men and 50\% women). ${ }^{22}$

The proportion of people who were overweight (39.8\%) and who had no posterior tooth pairs was lower than the results obtained in studies on the Indonesian population $(46.8 \%){ }^{23}$ Hilgert et al demonstrated that having no functional occluded tooth pairs or being edentulous increases the chance of being obese. ${ }^{24}$

Because excessive fat mass may mask malnutrition, $\mathrm{BCMI}$ reflecting the mass of muscles and tissue proteins adjusted for height was also calculated, in addition to BMI. ${ }^{25}$ In our analysis, we found a positive correlation between BCMI and chewing ability, expressed in terms of the number of teeth present, with masseter muscle tension evaluated with the help of ultrasound and palpation. Solemdal et al found a relationship between BCM and oral health status in hospitalized elderly people. ${ }^{26}$

BCM measurement with electrical bioimpedance has been used by other authors to assess skeletal muscle function. Low BCM was found to be associated with poor nutrition, low muscle strength, and reduced functional performance. ${ }^{27} \mathrm{~A}$ positive relationship has been shown to occur between $\mathrm{BCM}$ and $\mathrm{HGS},{ }^{26,28}$ and a negative correlation has been detected between the BCM and the

Table 2 Chewing ability variables in relation to demographics, nutritional indicators, medications, and comorbid diseases

\begin{tabular}{|c|c|c|c|c|c|c|}
\hline Variables & Present teeth $^{a}$ & Functional teeth ${ }^{a}$ & $\begin{array}{l}\text { Posterior } \\
\text { tooth pairs }\end{array}$ & $\begin{array}{l}\text { Difference in the } \\
\text { masseter muscle } \\
\text { thickness }^{\mathrm{a}}\end{array}$ & $\begin{array}{l}\text { Palpation of } \\
\text { masseter muscle } \\
\text { tension }^{\mathrm{b}}\end{array}$ & $\begin{array}{l}\text { Perceived } \\
\text { chewing } \\
\text { ability }^{\mathrm{b}}\end{array}$ \\
\hline Hand grip strength & $0.161,0.01$ & $0.026,0.673$ & 0.039 & $0.777,<0.001$ & $<0.001$ & 0.108 \\
\hline Timed up-and-go & $-0.014,0.83$ & $-0.127,0.053$ & $-0.131,0.045$ & $-0.249,<0.001$ & 0.015 & 0.129 \\
\hline Body mass index & $0.224,0.004$ & $-0.056,0.484$ & $-0.059,0.456$ & $0.372,<0.001$ & $<0.001$ & 0.198 \\
\hline Body cell mass index & $0.229,0.017$ & $0.067,0.492$ & $0.055,0.574$ & $0.777,<0.001$ & $<0.001$ & 0.721 \\
\hline Activities of daily living & $0.095,0.127$ & $0.037,0.557$ & $0.021,0.739$ & $0.214,0.001$ & 0.032 & 0.024 \\
\hline Prescribed medications & $-0.129,0.038$ & $0.054,0.387$ & $0.06,0.335$ & $-0.063,0.313$ & 0.141 & 0.085 \\
\hline
\end{tabular}

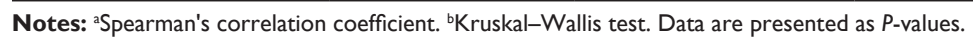


Table 3 Categories of masseter muscle tension versus dental status and physical fitness parameters, Kruskal-Wallis test

\begin{tabular}{|c|c|c|c|c|c|}
\hline Variable & $\begin{array}{l}\text { Total, } \\
\text { mean } \pm \text { SD }\end{array}$ & $\begin{array}{l}\text { Strong group, } \\
\text { mean } \pm \text { SD }\end{array}$ & $\begin{array}{l}\text { Weak group, } \\
\text { mean } \pm \text { SD }\end{array}$ & $\begin{array}{l}\text { Nil group, } \\
\text { mean } \pm \text { SD }\end{array}$ & $P$-value \\
\hline Hand grip strength & $18.9 \pm 8.8$ & $24.2 \pm 8.0$ & $16.4 \pm 6.9$ & $10.6 \pm 5.8$ & $<0.001$ \\
\hline Timed up-and-go & $11.9 \pm 5.3$ & $10.9 \pm 4.8$ & $12.3 \pm 5.3$ & $14.5 \pm 6 . \mid$ & 0.012 \\
\hline Body mass index & $25.7 \pm 4.3$ & $27.0 \pm 4.3$ & $24.7 \pm 3.9$ & $22.9 \pm 3.8$ & 0.001 \\
\hline Body cell mass index & $7.3 \pm 1.3$ & $8.1 \pm 1.3$ & $6.8 \pm 0.9$ & $6.6 \pm 1.0$ & $<0.001$ \\
\hline Activities of daily living & $16.1 \pm 4.9$ & $17.3 \pm 3.5$ & $16.2 \pm 5.1$ & $12.1 \pm 6$ & $<0.00$ I \\
\hline Prescribed medications & $6.9 \pm 3.0$ & $6.6 \pm 2.7$ & $6.8 \pm 3.0$ & $8.1 \pm 3.1$ & 0.036 \\
\hline Present teeth & $5.6 \pm 7.3$ & $8.2 \pm 8.2$ & $4.2 \pm 6.4$ & $2.5 \pm 4.2$ & $<0.001$ \\
\hline Functional teeth & $14.6 \pm 12.4$ & $16.9 \pm 11.3$ & $14.1 \pm 12.9$ & $9.0 \pm 12.8$ & 0.007 \\
\hline Posterior tooth pairs & $3.8 \pm 3.7$ & $4.4 \pm 3.4$ & $3.7 \pm 3.8$ & $2.4 \pm 3.7$ & 0.009 \\
\hline
\end{tabular}

Abbreviation: SD, standard deviation.

number of medications. ${ }^{26}$ Lauretani et al found correlations between HGS and the parameters determined by measurements of electric bioimpedance adjusted for body height. $^{29}$

The above-presented relationship between chewing ability and BMI and BCMI are in line with the results of other authors on the association between low chewing ability and limited food intake, ${ }^{30,31}$ limited food selection, ${ }^{31}$ and low micronutrient levels. ${ }^{32,33}$

A relationship between masticatory function, dietary selection, and nutritional intake is essential for maintaining musculoskeletal function. ${ }^{34}$

According to some authors, measurement of isometric $\mathrm{HGS}^{35}$ is a better marker/predictor of disability associated with low physical activity in elderly people than muscle mass. In our study, HGS was positively correlated with strong masseter muscle tension. Hämäläinen et al observed a correlation between HGS and the number of teeth present in a group of elderly men, but they did not find an association between the number of teeth and change in HGS over the course of 5 years of follow-up. ${ }^{36}$

Moreover, HGS was found to be significantly correlated with the strength and power of the muscles of the lower limbs, the cross-sectional size of the Achilles tendon, and knee bending torque. ${ }^{6}$

In our study, lower extremity performance evaluated from TUG test was negatively associated with DMMT, and the weaker palpation-rated masseter muscle tension was associated with longer TUG/poorer performance of the lower extremities.

Earlier studies have demonstrated in elderly people a relationship between lower extremity performance and perceived chewing ability ${ }^{11}$ or dental occlusion, assessed by the Eichner index. ${ }^{12}$

In our study, people with weaker masseter muscle tension were receiving more medications. In addition, people with weak masseter muscle tension had lower ADLs and were more dependent in ADLs, similar to people with low chewing ability assessed in the Kimura et al study, using color-changeable chewing gum. ${ }^{31}$ In addition, Takata et al revealed a relationship between low chewing ability and high-level functional capacity. ${ }^{37}$

Our research in institutionalized elderly people seems to confirm the hypothesis of a parallel weakening of the skeletal and the masseter muscles. ${ }^{4}$

\section{Conclusion}

There is a relationship in elderly people between chewing ability and physical fitness.

This study shows that efficiency of masseter muscles is related to physical fitness in elderly people. Assessment of the masseter muscle efficiency is a relatively simple, noninvasive test, which can be performed by a dentist, a geriatrician, or any other medical specialist to answer the question of whether

Table 4 Multiple logistic regression model, significant variables after adjusting for demographics: age, sex, and education

\begin{tabular}{lll}
\hline Variables & Odds ratio & 95\% confidence interval \\
\hline Number of teeth present & $\mathrm{I} . \mathrm{I} 55$ & $\mathrm{I} .057-\mathrm{I} .262$ \\
Hand grip strength & $\mathrm{I} .364$ & $\mathrm{I}-\mathrm{I} 50-\mathrm{I} .619$ \\
Body cell mass index & 3.623 & $\mathrm{I} .908-6.882$ \\
\hline
\end{tabular}


an elderly patient, in addition to a pharmacological treatment, also requires assistance in the modification of their diet. It may become an element of routine testing procedure.

The results encourage cooperation between dentists and geriatricians to improve health care for elderly people whose physical disability is often accompanied by dysfunction of the stomatognathic system.

\section{Disclosure}

The authors report no conflicts of interest in this work.

\section{References}

1. Avlund K, Holm-Pedersen P, Schroll M. Functional ability and oral health among older people: a longitudinal study from age 75 to 80 . J Am Geriatr Soc. 2001;49(7):954-962.

2. Holm-Pedersen P, Schultz-Larsen K, Christiansen N, Avlund K. Tooth loss and subsequent disability and mortality in old age. J Am Geriatr Soc. 2008;56(3):429-435.

3. Raadsheer MC, Van Eijden TM, Van Ginkel FC, Prahl-Andersen B. Human jaw muscle strength and size in relation to limb muscle strength and size. Eur J Oral Sci. 2004;112(5):398-405.

4. Iinuma T, Arai Y, Fukumoto M, et al. Maximum occlusal force and physical performance in the oldest old: the Tokyo oldest old survey on total health. J Am Geriatr Soc. 2012;60(1):68-76.

5. Ikebe K, Matsuda K, Kagawa R, et al. Association of masticatory performance with age, gender, number of teeth, occlusal force and salivary flow in Japanese older adults: is ageing a risk factor for masticatory dysfunction? Arch Oral Biol. 2011;56(10):991-996.

6. Cruz-Jentoft AJ, Baeyens JP, Bauer JM, et al; European Working Group on Sarcopenia in Older People. Sarcopenia: European consensus on definition and diagnosis: Report of the European Working Group on Sarcopenia in Older People. Age Ageing. 2010;39(4):412-423.

7. Goodpaster BH, Park SW, Harris TB, et al. The loss of skeletal muscle strength, mass, and quality in older adults: the health, aging and body composition study. J Gerontol A Biol Sci Med Sci. 2006;61(10):1059-1064.

8. Ansai T, Takata Y, Soh I, et al. Relationship between chewing ability and 4-year mortality in a cohort of 80-year-old Japanese people. Oral Dis. 2007;13(2):214-219.

9. Miura H, Kariyasu M, Yamasaki K, Arai Y, Sumi Y. Relationship between general health status and the change in chewing ability: a longitudinal study of the frail elderly in Japan over a 3-year period. Gerodontology. 2005;22(4):200-205.

10. Kim HY, Jang MS, Chung CP, et al. Chewing function impacts oral health-related quality of life among institutionalized and communitydwelling Korean elders. Community Dent Oral Epidemiol. 2009;37(5): 468-476.

11. Takata Y, Ansai T, Awano S, et al. Relationship of physical fitness to chewing in an 80-year-old population. Oral Dis. 2004;10(1):44-49.

12. Yamaga T, Yoshihara A, Ando Y, et al. Relationship between dental occlusion and physical fitness in an elderly population. $J$ Gerontol A Biol Sci Med Sci. 2002;57(9):M616-M620.

13. Hanada N, Tada A. The relationship between oral health status and biological and psychosocial function in the bedridden elderly. Arch Gerontol Geriatr. 2001;33(2):133-140.

14. Tada A, Watanabe T, Yokoe H, Hanada N, Tanzawa H. Relationship between the number of remaining teeth and physical activity in communitydwelling elderly. Arch Gerontol Geriatr. 2003;37(2):109-117.

15. Oral Health Surveys. Basic Methods. 4th ed. Geneva: World Health Organization; 1997:21-52.

16. Ohara Y, Hirano H, Watanabe Y, et al. Masseter muscle tension and chewing ability in older persons. Geriatr Gerontol Int. 2013;13(2): 372-377.
17. Podsiadlo D, Richardson S. The timed "Up and Go": a test of basic functional mobility for frail elderly persons. J Am Geriatr Soc. 1991;39(2): 142-148.

18. Bassey EJ. Demi-span as a measure of skeletal size. Ann Hum Biol. 1986;13(5):499-502.

19. World Health Organization. Physical status: The Use and Interpretation of Anthropometry-Report of WHO Expert Committee, Technical Report Series No. 854. Geneva: World Health Organization, 1995. Available from: http://www.who.int/childgrowth/publications/physical_status/en/. Accessed December, 2013.

20. Moore FD, Boyden CM. Body cell mass and limits of hydration of the fat-free body: their relation to estimated skeletal weight. Ann N Y Acad Sci. 1963;110(1):62-71.

21. Sytuacja zdrowotna ludności Polski w 2009 r., GUS, Warszawa 2011.

22. Sytuacja zdrowotna ludności Polski i jej uwarunkowania. Narodowy Instytut Zdrowia Publicznego-Państwowy Zakład Higieny, Warszawa 2012.

23. Adiatman M, Ueno M, Ohnuki M, Hakuta C, Shinada K, Kawaguchi Y. Functional tooth units and nutritional status of older people in care homes in Indonesia. Gerodontology. 2013;30(4):262-269.

24. Hilgert JB, Hugo FN, de Sousa ML, Bozzetti MC. Oral status and its association with obesity in Southern Brazilian older people. Gerodontology. 2009;26(1):46-52.

25. Talluri A, Liedtke R, Mohamed EI, Maiolo C, Martinoli R, De Lorenzo A. The application of body cell mass index for studying muscle mass changes in health and disease conditions. Acta Diabetol. 2003;40(0) (suppl 1):S286-S289.

26. Solemdal K, Sandvik L, Moinichen-Berstad C, Skog K, Willumsen T, Mowe M. Association between oral health and body cell mass in hospitalized elderly. Gerodontology. 2012;29(2):1038-1044.

27. Fiatarone MA, O'Neill EF, Ryan ND, et al. Exercise training and nutritional supplementation for physical frailty in very elderly people. N Engl J Med. 1994;330(25):1769-1775.

28. Figueiredo FA, Dickson ER, Pasha TM, et al. Utility of standard nutritional parameters in detecting body cell mass depletion in patients with end-stage liver disease. Liver Transpl. 2000;6(5):575-581.

29. Lauretani F, Russo CR, Bandinelli S, et al. Age-associated changes in skeletal muscles and their effect on mobility: an operational diagnosis of sarcopenia. J Appl Physiol (1985). 2003;95(5):1851-1860.

30. Lee MS, Huang YC, Wahlqvist ML. Chewing ability in conjunction with food intake and energy status in later life affects survival in Taiwanese with the metabolic syndrome. J Am Geriatr Soc. 2010;58(6): 1072-1080.

31. Kimura Y, Ogawa H, Yoshihara A, et al. Evaluation of chewing ability and its relationship with activities of daily living, depression, cognitive status and food intake in the community-dwelling elderly. Geriatr Gerontol Int. 2013;13(3):718-725.

32. Sahyoun NR, Lin CL, Krall E. Nutritional status of the older adult is associated with dentition status. $J$ Am Diet Assoc. 2003;103(1):61-66.

33. Sheiham A, Steele JG, Marcenes W, Tsakos G, Finch S, Walls AW. Prevalence of impacts of dental and oral disorders and their effects on eating among older people; a national survey in Great Britain. Community Dent Oral Epidemiol. 2001;29(3):195-203.

34. Moynihan PJ. The relationship between nutrition and systemic and oral well-being in older people. J Am Dent Assoc. 2007;138(4):493-497.

35. Janssen I, Heymsfield SB, Ross R. Low relative skeletal muscle mass (sarcopenia) in older persons is associated with functional impairment and physical disability. J Am Geriatr Soc. 2002;50(5):889-896.

36. Hämäläinen $\mathrm{P}$, Rantanen T, Keskinen $\mathrm{M}$, Meurman JH. Oral health status and change in handgrip strength over a 5-year period in 80-yearold people. Gerodontology. 2004;21(3):155-160.

37. Takata Y, Ansai T, Soh I, et al. Relationship between chewing ability and high-level functional capacity in an 80-year-old population in Japan. Gerodontology. 2008;25(3):147-154. 
Clinical Interventions in Aging

\section{Publish your work in this journal}

Clinical Interventions in Aging is an international, peer-reviewed journal focusing on evidence-based reports on the value or lack thereof of treatments intended to prevent or delay the onset of maladaptive correlates of aging in human beings. This journal is indexed on PubMed Central, MedLine,

CAS, Scopus and the Elsevier Bibliographic databases. The manuscript management system is completely online and includes a very quick and fair peer-review system, which is all easy to use. Visit http://www.dovepress. $\mathrm{com} /$ testimonials.php to read real quotes from published authors.

Submit your manuscript here: http://www.dovepress.com/clinical-interventions-in-aging-journal 